\title{
Status of the Mediterranean monk seal Monachus monachus in the western Sahara and the implications of a mass mortality event
}

\author{
Jaume Forcada $^{1, *}$, Philip S. Hammond ${ }^{2}$, Alex Aguilar ${ }^{1}$ \\ ${ }^{1}$ Department of Animal Biology, Faculty of Biology, University of Barcelona, Diagonal 645, 08028 Barcelona, Spain \\ ${ }^{2}$ NERC, Sea Mammal Research Unit, Gatty Marine Laboratory, University of St. Andrews, \\ St. Andrews, Fife KY16 8LB, Scotland, UK
}

\begin{abstract}
The largest aggregation of the highly endangered Mediterranean monk seals Monachus monachus is located on the Cap Blanc Peninsula on the coast of the western Sahara. Photographic identification of individuals was used in a capture-recapture analysis to estimate the abundance and composition of the colony during 1993 to 1998 . Results of the application of these techniques to Mediterranean monk seals were satisfactory, and allowed independent annual population estimates. No significant trends in abundance over the period 1993 to 1996 were detected, and the mean estimate for the period was 317 seals ( $C V=0.16 ; 95 \%$ CI: 237 to 447 ). Environmental changes affecting suitability of habitat, particularly food availability, are suggested as major factors for limited population recovery during this period. In spring 1997, a mass mortality event reduced the population size to 109 individuals $(\mathrm{CV}=0.14 ; 95 \% \mathrm{CI}: 86$ to 145$)$. Mortality was age-specific and resulted in a severe change in the stage composition of the population. Adults were the most affected, and therefore the proportion of juveniles increased from an initial $12 \%$ before the event to about $29 \%$ after. As a result of both the decrease in seal numbers and the change in population composition, the number of individuals potentially contributing to reproduction fell to about 77 or fewer. This number may not be enough to maintain genetic variability and overcome the effect of demographic stochasticity. The demographic changes caused by the die-off are expected to have both positive and negative effects on the reproductive success of the colony. However, they are undoubtedly factors which potentially threaten the stability and survival of the colony in the near future.
\end{abstract}

KEY WORDS: Capture-recapture Monachus monachus Photo-identification Population status Population trends - Western Sahara

\section{INTRODUCTION}

The Mediterranean monk seal Monachus monachus is a critically endangered species (red list, IUCN 1996) with a highly fragmented distribution. The world population has been estimated at 415 to 615 individuals, but the status of most sub-populations has not been consistently or adequately evaluated (Brasseur et al. 1997). Conservation efforts have been hampered by the absence of accurate population data.

\footnotetext{
- Present address: National Marine Fisheries Service, Southwest Fisheries Science Center, PO Box 271, La Jolla, California 92038, USA.E-mail: jforcada@sgilj.ucsd.edu
}

Two populations are currently accepted, one in the Mediterranean and the other in the Atlantic. In the Mediterranean, the species is distributed into local sub-populations, most of which appear to be nonviable in the long term or to have a high risk of extinction (Durant \& Harwood 1992). Apart from some notable examples in Greece, where the situation has improved and seals and their habitat seem reasonably secure, conflict between seals and humans continues to occur. Deliberate killing by fishermen or owners of fish farms trying to protect their nets from damage or who just want to eliminate a potential competitor, is still a major problem for most sub-populations. In addition, fragmentation has become an important problem. (see Aguilar 1998 for an extensive review). The size of 
some of the sub-populations is so small and they are located so far from other seal aggregations that genetic drift, consanguinity and environmental and demographic stochasticity are likely to cause their complete extinction in the short term (Harwood et al. 1998).

In the Atlantic there are 2 sub-populations: one near the Madeira Islands, and the other on the Cap Blanc Peninsula (see Fig. 1), on the coast of the western Sahara. This latter sub-population constitutes the largest aggregation of the species and is the only group which still preserves the structure of a colony (Marchessaux 1989a, González et al. 1997). This subpopulation was studied during the late 1980s until military activities and the deployment of land mines around the seal distribution range prevented the continuation of field research. At that point, the size of the colony had been estimated at about 130 seals (Francour et al. 1990). In 1990, 2 independent shipboard surveys gave seal counts of 81 and 91, respectively (El Amrani et al. 1992). In 1992, research activities were resumed on land and new counts of between 113 and 165 seals were produced for the period 1993 to 1994 (González et al. 1997). However, all these figures underestimate the true population size because the assessment methods used only accounted for the fraction of the colony present at the haul-out sites and surrounding waters. Additionally, the different methods used were not consistent, and any estimates of trends in abundance of the colony during this period are unlikely to be reliable.

No major threats to the colony have been identified in recent years, and until 1997 it was generally considered to be the only long-term viable subpopulation of the species. However, in May to June of that same year a severe event of mass mortality occurred. In only 2 mo seal numbers were greatly reduced, but definitive conclusions on the cause of mortality could be drawn (Harwood et al. 1998). The 2 likely causes were the intoxication through the consumption of fish contaminated with paralytic shellfish poison (PSP) saxitoxins (Hernández et al. 1998), and a morbilivirus outbreak (Osterhaus et al. 1997). Consequently, concerns for the viability and conservation of the colony have been expressed, reemphasizing the need for an updated and accurate evaluation of its status.

In this paper we report the results of a population analysis based on 6 yr of photo-identification data which was collected as part of a long-term capture-recapture study. The study was initiated in 1992 and aimed at estimating the main biological and population parameters of the Cap Blanc colony, and it also investigated the use of photo-identification in behavioural and monitoring studies (Grau et al. 1994). The period considered herein is from 1993 to 1998 , when systematic surveys were conducted on a regular basis at the main distribution areas of the colony. Composition and abundance of the colony for each year and trends in abundance over the study period were estimated from these surveys. The effects of mass mortality in 1997 were also investigated by the analysis of changes in composition and seal numbers in the colony immediately before and after the event. From the results of this analysis we provide an updated population assessment and a basis from which to evaluate the
Fig. 1 The peninsula of Cap Blanc, Western Sahara, showing the situation of caves, beaches and hauling out areas used by monk seals 
long-term viability of the colony. Moreover, our assessment outlines the difficulties to detect significant population trends with survey methods and the implications of mass mortality for the persistence of a small population.

\section{METHODS}

Seal colony and study area. The seal colony is distributed along the west coast of the Cap Blanc Peninsula, in the southern part of the western Sahara between $20^{\circ} 40^{\prime}$ and $21^{\circ} 20^{\prime} \mathrm{N}$ and $17^{\circ} 00^{\prime}$ and $17^{\circ} 20^{\circ} \mathrm{W}$ (Fig 1). The western coastline, stretching from Cap Barbas in the north to the tip of Cap Blanc in the south, consists of a succession of high cliffs which are constantly beaten by the Atlantic swell and are interspersed with sandy beaches. The largest concentration of the colony is at Costa de las Focas, where seals are found all year round. In this area seals haul-out and breed in narrow beaches inside 2 main caves, named Caves 1 and 3 by Marchessaux (1989a). Several solitary bulls defend individual aquatic areas, and some haul-out on open beaches at the tip of Cap Blanc, south of Caves 1 and 3, and also in an area called Zone 4 (Fig. 1) to the north of the main breeding caves. These bulls can also be observed with the rest of the colony at the haul-out sites in Caves 1 and 3. Gonzalez et al. (1997) provide a detailed description of the species distribution at Cap Blanc.

Photographic identification of seals. Natural marks, scars, wounds and disruptive coloration patterns were used to identify seals from photographs. Colour slides (ISO ${ }^{\otimes} 100-200$ ) of the different views of the most reliable identifying features were obtained from swimming seals. Among these views, the right side of the head was preferentially selected, because this was sufficient for unequivocal recognition. All adult, subadult and juvenile seals were photographed regardless of their markings.

Slicles were objectively graded for photographic quality and distinctiveness (Forcada \& Aguilar 1996), and included in a catalogue of identified individuals

Table 1. Details of the photo-identification sampling surveys conducted in the field during the study period

\begin{tabular}{|cccc|}
\hline Year & $\begin{array}{c}\text { Annual } \\
\text { sampling period }\end{array}$ & $\begin{array}{c}\text { Days } \\
\text { of effort }\end{array}$ & $\begin{array}{c}\text { Mean sampling } \\
\text { efficiency }\end{array}$ \\
\hline 1993 & May - Jun & 16 & 1.47 \\
1994 & Mar - May & 30 & 1.82 \\
1995 & Apr - Jun & 32 & 2.23 \\
1996 & Apr - Jul & 34 & 2.16 \\
1997 & Jul - Oct & 36 & 1.29 \\
1998 & May - Aug & 29 & 1.22 \\
\hline
\end{tabular}

(Cantos et al. 1998). Captured individuals were considered those with good quality slides of the right side of the head. According to this, in this photo-identification survey an individual effectively photographed was considered captured. Slides of identified seals from different surveys were matched with minimum error rates by experienced researchers. Natural marks were considered stable during the study period, as shown by the results of the reliability tests conducted (Forcada \& Aguilar 1996).

Capture-recapture surveys. Photo-identification slides were taken in systematic surveys throughout the known distributional range of the colony, but a higher sampling effort was made in Caves 1 and 3. Annual sampling periods consisted of 1 to 3 consecutive surveys and comprised between 16 and 36 effective field days (Table 1). An effective field day was a day in which at least 6 to $8 \mathrm{~h}$ of good weather and sea state conditions allowed us to obtain good slides of seals. Sea state, measured according to the Beaufort scale, was considered good in conditions between 0 and 4 . Identification histories of seals, organized into capture occasions, were extracted from the data collected in annual periods. Each occasion comprised data from 2 to 4 consecutive field days, and 5 to 8 d separated occasions to allow for the random mixing of seals at the haul-out site. The optimum number of days between occasions was assumed equal to the interval in days at which mean capture probabilities $(\bar{p})$ began to leveloff (Fig, 2). Capture probabilities were estimated as the proportion of identified seals that were recaptured on a certain day of the interval, as in Pollock et al. (1990). The mean probability was obtained from 15 replicated estimations of capture probabilities. In each replicate,

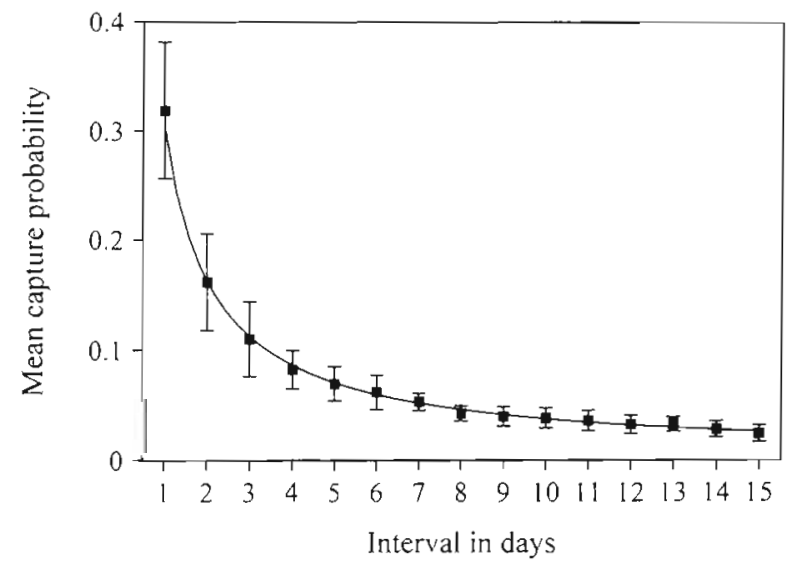

Fig. 2. Relationship between mean capture probabilities, with $95 \%$ confidence limits, and interval length in days. Capture probabilities are estimated as the proportion of identified seals recaptured on the last day of the interval. The mean probability at cumulative intervals of 1 to $15 \mathrm{~d}$ is obtained from 15 replicated sets of identification histories 
capture probabilities were estimated at intervals of 1 to $15 \mathrm{~d}$ between the capture and recapture. Capture probabilities at each interval were averaged over the 15 replicates.

Annual sampling periods were consistent in dates from 1993 to 1996, but the pattern and variable number of effective field days gave a different number of capture occasions in each year. After the 1997 mass mortality there was a reduced number of seals at the usual distribution range, and a higher number of field days for each capture occasion was required to attain a reasonable sample size.

Each photographed seal was assigned to a morphological group: juvenile, medium-sized seal, large grey seal, or black male, following the classification by González et al. (1997). The number of captured seals in each annual period was considered representative when the proportions of morphological groups did not differ significantly from those in counts at the haul-out sites (Forcada \& Aguilar 1996). Systematic counts, conducted throughout each year, also provided an estimate of the relative sampling efficiency $(E f)$ with the index

$$
E f_{i}=\frac{\sum_{i=1}^{m} n_{i j}}{\sum_{i=1}^{m}\left[\eta_{i j}\left(1-\hat{c}_{i j}\right)\right] \hat{d}_{i j}}
$$

where $n_{i j}$ is the number of individuals of morphological group $i$ captured in survey $j, \eta_{i j}$ is the maximum number of counted seals from group $i, c_{i j}$ is the proportion of individuals from group $i$ with poor quality slides, and $d_{y j}$ the proportion of distinctive seals (with reliable marks) from group $i$. The sampling efficiency of an annual period was estimated as the mean efficiency over capture occasions. Surveys in Table 1 with a mean sampling efficiency close to or above 1 were considered representative.

All data sets included the subadult and adult stages of the colony, which correspond to medium-sized seals, and black males and large grey seals, respectively. Juveniles were less well-marked and identifiable and had very low recapture rates compared to the other age stages, and therefore they were not included in the capture-recapture analysis. Nevertheless, their proportions were taken into account to correct abundance estimates for non-distinctive seals and also to analyze the composition of the colony using photo-identification data

The proportion of identifiable seals from the total population size (d) was estimated for each annual sampling period by the ratio of seals caught to those that were distinctive. From each period we derived a random sample of captured seals, with each individual represented by 1 good or excellent quality slide. Because the capture probabilities were initially esti- mated to be lower for black males (i.e. black males had a lower proportion of good quality slides), a proportionally larger amount of time was spent photographing seals from that group.

Analysis. Composition of the colony: The stage composition of the colony was estimated from the probability $(q)$ of captured individuals belonging to each morphological group: juveniles, medium-sized seals, large grey seals and black males. Given $v_{j}$, the number of photographed seals of group $j$ from a sample of $n$ seals, the probability of a seal belonging to group $j$ was

$$
\hat{q}_{j}=\frac{v_{j}}{n}
$$

Simultaneous $90 \%$ confidence intervals (CI) for each $q_{\text {; }}$ were obtained following Scheffé (cf. Miller 1981),

$$
\hat{q}_{j} \pm\left(\chi_{g-1,010}^{2}\right)^{\frac{1}{2}}\left[\frac{\hat{q}_{j}\left(1-\hat{q}_{j}\right)}{n}\right]^{\frac{1}{2}}
$$

where $g$ is the number of different morphological groups considered. The composition of the colony was analyzed independently for each year, and differences among years were tested using Pearson's $\chi^{2}$ goodnessof-fit test.

The bias arising from differences in the identifiability of individuals was assessed according to Forcada \& Aguilar (1996). Thus, a larger proportion of time was spent approaching black males, which were less easy to be photographed. Therefore, a fixed number of 15 effective field days from each annual sampling period was chosen to derive a random sample for each year. While black males could be photographed in any day, at least 5 of the $15 \mathrm{~d}$ were especially dedicated to obtain slides from individuals of this group. With lessmarked seals, like juveniles, a larger number of photographs was taken in order to obtain a well-detailed record of even the more subtle marks.

Abundance: The size of the Cap Blanc colony was estimated for each year from 1993 to 1998. Annual sampling periods were assumed demographically closed, with no migration of individuals. Each set of annual jdentification histories was analyzed by multisample capture-recapture models for closed populations. The models taken into account were $M_{1}, M_{h}$ and $M_{t h}$, following the notation by Otis et al. (1978). These models allow for variation in capture probabilities over time or capture occasions $\left(M_{t}\right)$, individual seals known as heterogeneity $\left(\mathrm{M}_{h}\right)$ and time and individual seals $\left(\mathrm{M}_{\mathrm{th}}\right)$. Heterogeneity in capture probabilities appears to always be present in studies of natural populations (Eberhardt 1969, Carothers 1973, Hammond 1986). Thus, models accounting for such variability were preferentially selected, particularly model $\mathrm{M}_{\mathrm{t} \hat{\mathrm{k}}}$. Estima- 
tors associated with these models and considered in the analysis were: Darroch's maximum likelihood estimate (MLE) (Darroch 1958) for $\mathrm{M}_{\mathrm{t}}$, Jackknife (Burnham \& Overton 1978,1979$)$ for $M_{h}$, and Chao's nonparametric estimator (Chao et al. 1992) for $M_{\mathrm{Hh}}$. Goodness-of-fit tests (Otis et al. 1978) and the model selection algorithm in the program CAPTURE (Rexstad \& Burnham 1992) were used to test departures from the assumption of equal capture probabilities among seals and capture occasions. The best model and appropriateness of each estimator were selected according to sample size, sample coverage, the coefficient of variation (CV) of the mean capture probability and the robustness under different sources of variation in capture probabilities. The sample coverage $(C)$ is defined as the proportion of the total individual effects $\left(p_{1}\right)$ on the first capture probability. Chao et al. (1992) provide unbiased estimators, which have been used in this analysis. The coefficient of variation of the mean capture probability, $C V(\bar{p})$, was

$$
C V(p)=\frac{\left[\frac{\sum_{i=1}^{m}\left(p_{i}-\bar{p}\right)^{2}}{N}\right]^{\frac{1}{2}}}{\bar{p}}
$$

where $\bar{p}$ is the mean capture probability. When $C V(p)$ $=0$, all $p_{i}$ were assumed equal; otherwise there was individual variation or heterogeneity in capture probability. Chao et al. (1992) provide unbiased estimators of $C V(p)$, which are also implemented in the program CAPTURE and used in this analysis. The best abundance estimator was then selected following the recommendations of Lee \& Chao (1994).

Estimation methods assumed that seals did not lose their marks during the sampling period and that all marked seals were correctly identified on each capture occasion. These assumptions appear to be fulfilled in the present study (Forcada \& Aguilar 1996). However, capture-recapture abundance estimates only referred to the proportion of the colony with distinctive natural marks. In order to account for non-distinctive seals, including all juveniles, abundance estimates were scaled up with the mean proportion of seals with reliable marks in the colony $(\bar{d})$. Thus, abundance was obtained as

$$
\hat{N}=\frac{\hat{N}_{d}}{\bar{d}}
$$

where $\hat{N}_{d}$ is the estimated size of the distinctive proportion of the colony, and variance of $\hat{N}$ was estimated using the delta method (e.g. Seber 1982), as

$$
\operatorname{vâr}(\hat{N})=\hat{N}^{2}\left[\frac{\operatorname{vâr}\left(\hat{N}_{d}\right)}{\hat{N}_{d}^{2}}+\frac{\operatorname{vâr}(\hat{d})}{\hat{d}^{2}}\right]
$$

where, from Thompson (1992),

$$
\operatorname{vatr}(\hat{d})=\left(\frac{\hat{N}-n}{\hat{N}}\right) \frac{\hat{d}(1-\hat{d})}{n-1}
$$

and $n$ is a random sample of captured seals (i.e. the number of seals captured in an annual sampling period). A $95 \%$ CI was constructed for each estimate assuming that $\log \left(N-m_{t+1}\right)$ is an approximately normal random variable (Burnham et al. 1987, Chao 1989), where $m_{t+1}$ is the number of distinctive seals captured during the sampling period. Following Chao (1989) the log-normal $95 \%$ CI was estimated as

$$
\left[m_{t+1}+\frac{\left(\hat{N}-m_{t+1}\right)}{V}, m_{t+1}+\left(\hat{N}-m_{t+1}\right) V\right]
$$

where

$$
V=\exp \left(1.96\left\{\ln \left[1+\frac{\operatorname{var}(\hat{N})}{\left(\hat{N}-m_{t+1}\right)^{2}}\right]\right\}^{\frac{1}{2}}\right)
$$

Estimates of $\hat{N}_{d}$ and $\operatorname{var}\left(\hat{N}_{d}\right)$ were computed with the program CAPTURE (Rexstad \& Burnham 1992).

Trends in abundance: Changes in abundance of $\mathrm{Me}$ diterranean monk seals on Cap Blanc were investigated for the period 1993 to 1998 . For the period 1993 to 1996, the rate of change, assumed exponential, was computed with a weighted least-squares regression of point capture-recapture estimates against time. Abundances were log-transformed before fitting the regression model. Following Barlow et al. (1997), each point estimate was weighted by the inverse of its variance to account for differences in precision. Variance of $\hat{N}$ was estimated as $\ln \left[1+C V^{2}(N)\right]$.

We assessed the variability of the rate of change (the back-transformed slope) using a Monte Carlo simulation for measuring a slope using linear regression. We assumed the initial slope equal to the estimated rate of change, and the variance of abundance determined from the estimated CVs. We obtained a $95 \% \mathrm{CI}$ from the percentiles of 10000 replicates.

\section{RESULTS}

\section{Composition of the colony}

From 1993 to 1998,52 juveniles, 173 medium-sized and large grey seals, and 31 black males were individually identified. Table 2 details the composition of the population by year during the study period. From the 24 females that were seen nursing, 12 were catalogued by observers as being medium-sized grey seals and 12 as large grey seals; given that large grey seals are indeed more abundant in the population than mediumsized seals, it is reasonable to assume that the latter are 
Table 2. Monachus monachus. Composition of the colony, expressed in both absolute numbers ( $v$ ) and as a proportion of the total (with simultaneous $90 \%$ confidence limits as derived from multinomial theory in parentheses) by morphologic group in each year, estimated from a sample of identified seals $(n)$. Proportions of each group were estimated assuming independence between groups. Data for 1997 correspond to the papulation that survived mass mortality

\begin{tabular}{|c|c|c|c|c|c|c|c|c|}
\hline \multirow[t]{2}{*}{ Year } & \multicolumn{2}{|r|}{ Juveniles } & \multicolumn{2}{|c|}{ Medium-sized seals } & \multicolumn{2}{|c|}{ Large grey seals } & \multicolumn{2}{|c|}{ Black males } \\
\hline & v & Proportion & $v$ & Proportion & $v$ & Proportion & $v$ & Proportion \\
\hline 1993 & 5 & $0.10(0.01-0.20)$ & 21 & $0.41(0.24-0.58)$ & 20 & $0.39(0.22-0.56)$ & 5 & $0.10(0.01-0.20)$ \\
\hline 1994 & 16 & $0.13(0.06-0.21)$ & 32 & $0.27(0.17-0.37)$ & 48 & $0.40(0.29-0.51)$ & 24 & $0.20(0.11-0.29)$ \\
\hline 1995 & 18 & $0.14(0.07-0.22)$ & 36 & $0.29\{0.19-0.39\}$ & 46 & $0.37(0.26-0.47)$ & 26 & $0.21(0.12-0.30)$ \\
\hline 1996 & 13 & $0.10(0.03-0.17)$ & 37 & $0.29(0.19-0.38)$ & 57 & $0.44(0.33-0.55)$ & 23 & $0.18(0.09-0.26)$ \\
\hline 1997 & 20 & $0.29(0.15-0.43)$ & 24 & $0.35(0.20-0.49)$ & 18 & $0.26(0.13-0.39)$ & 7 & $0.10(0.01-0.19)$ \\
\hline 1998 & 19 & $0.31(0.16-0.46)$ & 18 & $0.30(0.15-0.44)$ & 17 & $0.28(0.14-0.42)$ & 7 & $0.12(0.01-0.22)$ \\
\hline
\end{tabular}

all adult and involved in reproduction. The composition of the colony by morphological group showed little variation between 1993 to 1996. Proportions of seals significantly changed only from 1993 to $1994\left(\chi^{2}=43,3 \mathrm{df}\right.$; $p<0.001$ ) due to an increase in observations of black males in 1994. However, the number of field days in 1993 was too low to obtain a representative sample of identified black males. Therefore, the estimated composition of 1993 may not be reliable or comparable to that of subsequent years.

Highly significant changes $\left(\chi^{2}=131,3 \mathrm{df} ; \mathrm{p}<0.001\right)$ were observed after July 1997 (Table 2). The mass mortality had a major impact on the adult population. The proportion of juveniles increased from 10 to $29 \%$, and that of medium-sized seals from 29 to $35 \%$. In contrast, the proportions of large grey seals decreased from 44 to $26 \%$ and those of black males from 18 to $10 \%$.

\section{Abundance}

The relatively low number of photographed seals from each stage in each year (Table 2) ruled out a capturerecapture analysis stratified by morphological group. Despite this was a problem under low photographic effort conditions (e.g. surveys of less than 10 effective field days), extending the sampling period up to at least $20 \mathrm{~d}$ ensured that capture probabilities did not differ significantly among adult seal groups. Thus, identification histories from all stages except juveniles were pooled in a common data set. Independent sets were then created for each year to produce annual abundance estimates of the colony.
When plotted against time, mean capture probabilities stabilized in values which were not significantly lower than 0.05 by the end of the first week of the survey (Fig. 2). This indicates that seals were mixed at random, and the probability of resighting seals which had already been identified was not higher than that of sighting those which had not been seen before. Consequently, the choice of an interval length of 5 to $8 \mathrm{~d}$ between capture occasions allowed some turnover of seals at the haul-out sites, thus minimizing heterogeneity in capture probabilities. In addition, if this period was greater than $8 \mathrm{~d}$, the probability of photographing seals which had not been seen previously was higher. However, an interval of $8 \mathrm{~d}$ would have expanded the total sampling period, thus reducing the number of different capture occasions. Therefore, we chose to consider intervals of about 5 to $6 \mathrm{~d}$.

Sampling conditions varied between years, and this resulted in different types of variation in capture probabilities. With this in mind, we selected different capture-recapture models for different years in order to obtain the best fit to the data and therefore the most accurate abundance estimate for each year.

In 1993 and 1994 sampling efficiency was lower than in subsequent years (Table 1), data were sparse (low $\bar{p}$ ), and the CV of the capture probabilities was

Table 3. Monachus monachus. Results of the photo-identification sampling to estimate abundance, with statistics and parameters computed for best model selection. Models with asterisks were also selected by the goodness-of-fit tests in CAPTURE (Rexstad \& Burnham 1992). (Models and parameters defined in 'Method: Analysis')

\begin{tabular}{|c|c|c|c|c|c|c|}
\hline Year & $\begin{array}{c}\text { Sampling } \\
\text { occasions } \\
(t)\end{array}$ & $\begin{array}{c}\text { Distinctive } \\
\text { seals } \\
\left(m_{i+1}\right)\end{array}$ & $\begin{array}{c}\text { Sample } \\
\text { coverage } \\
\text { (C) }\end{array}$ & $\begin{array}{l}\text { Mean capture } \\
\text { probability } \\
(\bar{p})\end{array}$ & $C V(p)$ & Estimator \\
\hline 1993 & 10 & 44 & 0.28 & 0.02 & 0.33 & Chao's $M_{\text {th }}\left(M_{t h}\right)$ \\
\hline 1994 & 14 & 126 & 0.68 & 0.06 & 0.30 & Chao's $M_{t h}\left(M_{t h}\right)$ \\
\hline 1995 & 14 & 154 & 0.65 & 0.06 & 0.01 & Darroch's MLE $\left(\mathrm{M}_{1}\right)^{\circ}$ \\
\hline 1996 & 15 & 107 & 0.43 & 0.03 & 0.01 & Darroch's MLE $\left(\mathrm{M}_{\mathrm{t}}\right)^{\circ}$ \\
\hline 1997 & 6 & 49 & 0.89 & 0.30 & 0.35 & Chao's $\mathrm{M}_{\mathrm{th}}\left(\mathrm{M}_{\mathrm{th}}\right)^{\text {. }}$ \\
\hline 1998 & 6 & 42 & 0.82 & 0.25 & 0.37 & Chao's $M_{t h}\left(M_{t h}\right)^{*}$ \\
\hline
\end{tabular}


above $30 \%$ (Table 3). In addition, goodness-of-fit tests indicated heterogeneity in capture probabilities. Therefore, model $\mathrm{M}_{\mathrm{th}}$ was selected as the most appropriate. Under this model, Chao's estimator is preferable when sample coverage is about $50 \%$, or there are enough data to generate a stable estimator of $C V(p)$ (Chao et al. 1992, Lee \& Chao 1994). Sample coverage was high in 1994 but went down to $30 \%$ in 1993 (Table 3), when data were more sparse. Because other estimators which are robust to heterogeneity are not very efficient under these conditions and the number of capture occasions was high in both years, Chao's $M_{\text {th }}$ was used to compute abundance in 1993 and 1994.

In 1995 and 1996, mean capture probabilities were low but their CVs were estimated below 0.01 by CAPTURE (Table 3), indicating no heterogeneity. Goodness-of-fit tests showed highly significant $(p<0.001)$ time variation in capture probabilities in both years. Sample coverage was $65 \%$ in 1995 and $43 \%$ in 1996. Since heterogeneity did not need to be taken into account, Darroch's MLE (Darroch 1958) was used to compute abundance in 1995 and 1996. In these cases Chao's model $M_{t h}$ consistently overestimates abundance (Chao et al. 1992).

In 1997 and 1998, the reduced number of seals at the haul-out sites required a mean number of 6 consecutive field days per capture occasion in order to obtain a $\bar{p}$ of 0.3 in 1997 and of 0.25 in 1998. As a result of changes in the seal occupation of caves after the mass mortality (J. Forcada unpubl. data), the sampling efficiency was not high despite the high number of effective field days (36 in 1997 and 29 in 1998). Goodnessof-fit tests indicated individual variation and time specificity in capture probabilities. Heterogeneity was high, with an estimated $C V(p)$ of 0.35 in 1997 and 0.37 in 1998, and sample coverage was $89 \%$ in 1997 and $82 \%$ in 1998 . Therefore Chao's $M_{\mathrm{th}}$ was used to compute abundance in both years.

Correction factors for non-distinctive seals varied from 0.58 to 0.78 , depending on the number of juveniles and medium-sized seals present in each year (Table 4). The lowest proportion of distinctive seals was observed in 1997 and 1998 when the reduction in adult numbers from the mass mortality increased the proportion of juveniles by $20 \%$. Table 4 contains the corrected abundance estimates for each year, with coefficients of variation and log-normal $95 \%$ confidence intervals.

Abundance estimates were similar from 1993 to 1996, with a mean value

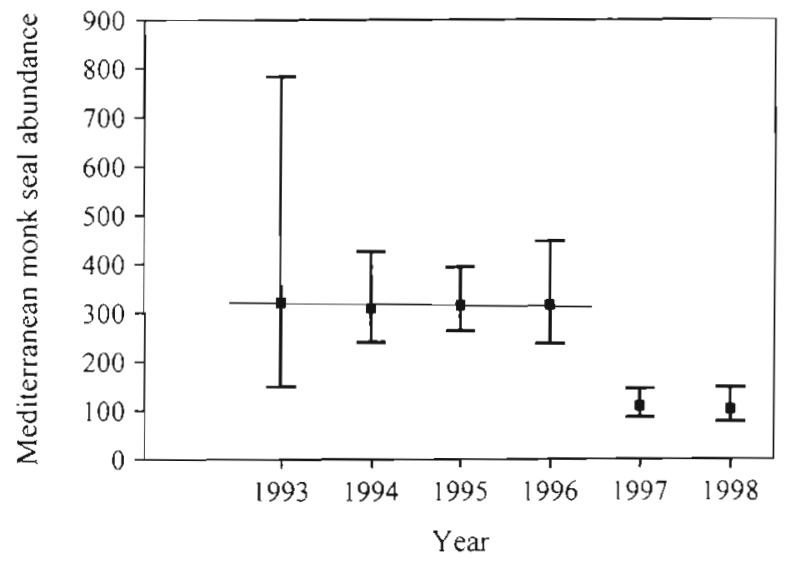

Fig. 3. Monachus monachus. Abundance estimates of Mediterranean monk seals in Cap Blanc from 1993 to 1998, with log-normal $95 \%$ confidence intervals. The exponential regression line corresponds to the fitted least-squares model to the natural logarithm of the point estimates from 1993 to 1996 , weighed by the inverse of their log-transformed variances

of 317 seals $(\mathrm{CV}=0.16 ; 95 \% \mathrm{CI}: 237$ to 447$)$. After the 1997 mass mortality, the colony was reduced by $66 \%$ to a surviving population estimated at 109 seals. Coefficients of variation of estimates ranged from 0.10 to 0.17 , except for 1993 when the sample size was low and the CV was estimated to be 0.46 .

\section{Trends in abundance}

The least-squares regression line, fitted to the 4 independent abundance estimates from 1993 to 1996, had a slope of -0.0073 (Fig. 3) after the back-transformation, but was not significantly different from $0(\mathrm{p}=$ 0.381 ). The low and high limits of the estimated $95 \%$ CI were -2.0185 and 1.9739 , respectively.

The probability of obtaining significant declines for small populations in short time series is usually low

Table 4. Monachus monachus. Estimates of abundance of Mediterranean monk seals at the colony of Cap Blanc from 1993 to 1998, estimated from independent capture-recapture experiments. Also detailed are the proportions of identifiable seals ( $d$, with standard error in parentheses), the estimated coefficients of variation of the abundance estimate and its log-normal $95 \%$ confidence intervals

\begin{tabular}{|cccccc|}
\hline Year & $\begin{array}{c}\text { Proportion } \\
\text { identifiable }(d)\end{array}$ & $\begin{array}{c}\text { Abundance } \\
(\hat{N})\end{array}$ & $\begin{array}{c}\text { Coefficient } \\
\text { of variation }\end{array}$ & \multicolumn{2}{c|}{$\begin{array}{c}\text { Log-normal 95\% } \\
\text { confidence interval } \\
\text { Low limit High limit }\end{array}$} \\
\hline 1993 & $0.61(0.17)$ & 322 & 0.46 & 149 & 783 \\
1994 & $0.68(0.09)$ & 311 & 0.15 & 240 & 426 \\
1995 & $0.76(0.07)$ & 316 & 0.10 & 263 & 394 \\
1996 & $0.78(0.06)$ & 317 & 0.16 & 237 & 447 \\
1997 & $0.58(0.06)$ & 109 & 0.14 & 86 & 145 \\
1998 & $0.58(0.04)$ & 103 & 0.17 & 77 & 148 \\
\hline
\end{tabular}


(Taylor \& Gerrodette 1993). In our study, the high variability in the 1993 abundance estimate makes the detection of a decline even more difficult. A power analysis with the program TRENDS (Gerrodette 1993) indicated that, assuming an exponential change over 4 yr, an average $C V$ of 0.15 , and high statistical power $(\beta=0.05)$, the minimum detectable annual decline would be of -0.50 . Thus, no trends before 1997 could be detected. However, owing to the low slope of our trend analysis, it is believed that if there was any annual rate of change in the population, it was likely to be low.

\section{DISCUSSION}

\section{Reliability of methods and accuracy of estimates}

Capture-recapture experiments based on photoidentification have a number of advantages for estimating the abundance of Mediterranean monk seals at Cap Blanc: the unique natural markings in a high proportion of the population, the small size but high density of the colony and the non-disruptive way in which these data were collected. A disadvantage, however, is that sampling techniques based upon small populations often result in high variances and the asymptotic properties of the estimators are lost (Otis et al. 1978, Hiby \& Jeffery 1987). In the following paragraphs we address the validity of the analysis in relation to the underlying assumptions of capturerecapture models.

We selected our data sets for analysis to be able to assume geographic and demographic closure. This is important because closed population models are more robust to variation in capture probabilities than those designed for open populations, therefore permitting greater accuracy in population estimates (Otis et al. 1978, Pollock et al. 1990). In addition, abundance estimates calculated on the assumption of demographic closure can be computed independently for each year and thus be used to establish time trends.

However, all the estimates herein reported may be negatively biased for at least 2 reasons. Firstly, Mediterranean monk seals are undoubtedly found outside the surveyed areas. Secondly, because annual sampling periods were reduced in time to allow demographic closure, the turnover of migrating seals may be incomplete. But in both cases, biases are not likely to be significant because the surveys covered most of the known range of the species on Cap Blanc (Gonzalez et al. 1997) and mean residency times of seals around the haul-out sites were longer than the duration of the sampling periods, thus indicating low migration rates (J. Forcada unpubl. data). Therefore, annual samples of identified seals were likely to be representative of the total population.

The surveys were designed to minimize variation in capture probabilities, but this was not entirely eliminated. The most common sources of variation were the sampling conditions on each occasion and the inherent differences in capture probabilities between individuals (heterogeneity). These differences were related to the variable haul-out patterns between groups of seals; for instance, near-term pregnant or lactating females were more likely to be found at haul-out sites than other seals, but black males, which not only hauled out in the caves but also in other areas not frequented by the other seals, were less likely to be captured. Under these conditions, and because no behavioral response to capture (reactions of seals to the photographer) was observed after the first capture, variation in $p$ was dealt with by focusing on model $M_{\text {in }}$ from Otis et al. (1978). The robustness of available estimators under model $M_{t h}$ is limited in extreme cases, such as when high heterogeneity exists, which tends to bias the results low (Chao et al. 1992). However, in this study, heterogeneity as estimated by $C V(p)$ was $37 \%$ at the most. Thus, estimators selected according to this parameter in each sampling period were considered to give robust estimates

Capture probabilities could also vary through the use of poor quality slides to determine recaptures and the variable distinctiveness among seals. In that respect, the objective grading and further selection of good or excellent slides made in this study prevented false new identifications in each sampling period. Although the probability of photographing a seal for its distinctiveness could not be estimated, it is unlikely that photographers in the field preferentially selected well-marked individuals. Therefore, provided that slides were of good quality, any marked seal could be captured. Forcada \& Aguilar (1996) found no correlation between recapture rates and different distinctiveness for different morphological groups, and concluded that distinctiveness is unlikely to significantly bias capture-recapture abundance estimates. Despite the identified limitations underlying both the data and the capture-recapture models, we consider that the results presented in this paper are unlikely to be significantly biased.

\section{Demographic trajectory and status of the population}

The CVs of all abundance estimates, except the one corresponding to 1993, fall within the range of acceptable values for management purposes as defined by White et al. (1982) and Pollock et al. (1990). Although the confidence limits are broader than desired for a 
rare species, they indicate that the number of seals on Cap Blanc before the spring 1997 die-off was around only 300 , a number which is vulnerable to catastrophes and mass mortalities.

In the past, Mediterranean monk seals appeared to have been abundant in the western Sahara. Neolithic deposits contained burnt seal bones, indicating human consumption of seals at that time. However, during the middle ages, and probably until the 16th century, Spanish and Portuguese sealing expeditions decimated the local colonies for fur and oil (Aguilar 1998). Some of these colonies, like the one which inhabited the sand bank in Dakhla Bay (Île des Hérons), appear to have been composed of several hundred individuals (Monod 1923). Apart from the sealing episode, the area has been sparsely populated by humans for several centuries, thus limiting possible adverse interactions with seals.

During the first half of the present century the presence of monk seals along the coast was recorded by a number of researchers (Monod 1923, Gruvel 1924, Morales-Agacino 1945, 1950, Valverde 1957). They were relatively abundant around Cap Bojador, near Dakhla Bay, between Cap Barbas and Cap Corbeiro and particularly on the Cap Blanc Peninsula. At present the species appears to have completely disappeared north of Cap Bojador. Some occasional sightings during the last 20 yr have been made in the section of coastline between Cap Bojador and Cap Barbas, but recent surveys in that region show that there is no permanent colony there; therefore, reports are probably of strays from populations located further south. The political instability in the region has prevented detailed surveys of the shore between Cap Barbas and the Aguerguer (Guerguerat), but sightings in open waters off the area as well as reports from fishermen and seafarers indicate that some individuals are found in the region (Marchessaux 1989b, Bayed 1994, Aguilar 1998, University of Barcelona unpubl. data). The largest seal aggregation in the area is undoubtedly the one inhabiting the Cap Blanc Peninsula.

Population numbers in this colony were thought to remain stable during the late 1980s (Francour et al. 1990), but this cannot be ascertained because of the lack of effective assessment methods. According to the results of the present study, numbers are likely to have been stationary from 1993 to April 1997. Some seal populations depleted by sealing have shown dramatic recoveries from extremely low numbers. For example, Antarctic fur seals in South Georgia increased from a few dozen individuals in the 1930s to about 369000 in 1976 (Payne 1979). In 1890, northern elephant seals were reduced to perhaps as few as 20 individuals on Guadalupe Island (Bartholomew \& Hubbs 1960), but numbers built up to an estimation of 127000 in 1991
(Stewart et al. 1994). These recoveries were accompanied by rapid recolonization of former distribution ranges. Other seal species, particularly of the genus Monachus, have followed different trajectories. The Caribbean monk seal is now considered extinct, after a progressive decline in the first half of the present century, and a high fragmentation of its original distribution range (Boyd \& Stanfield 1998). The Hawaiian monk seal population has been severely reduced in the last decades. Numbers at different distribution areas have followed different trends, according to various problems, such as anthropogenic pressure, biased sex ratios or significant decreases in survival of the young individuals. In consequence, recovery to former numbers in the short term is considered to be very unlikely (Gilmartin \& Eberhardt 1995). The reasons for the absence of demographic recovery of Mediterranean monk seals in the western Sahara population, despite the apparent absence of threats and availability of example habitat to recolonize, are unknown.

This colony has been closely monitored since the 1980s, and the existence of human-related direct threats to seals has not been apparent. Pollutant levels, as expected by the remoteness of the location from agricultural or industrial activities, are extremely low (Borrell et al. 1997), and kills or disturbances caused by fishing or other human activities are non-existent or negligibie, at least in the area around the caves (Marchessaux 1989a, University of Barcelona 1997). Nevertheless, the effect of pelagic fisheries needs to be assessed, since its effect cannot be detected in the breeding areas.

A number of natural factors may limit growth in pinniped populations. Despite the presence of sharks and killer whales in the area, no attacks on seals have been observed nor have seal corpses been found with signs of predator action. Incidence of disease has not been properly surveyed in this population, but a virus closely related to the dolphin morbillivirus (DMV) was isolated from tissues of 3 individuals that died during the spring 1997 die-off. Serum antibodies to canine distemper virus (CDV) were also detected in 4 of the 17 blood samples collected during the event (Osterhaus et al. 1997). While research on the role of the morbillivirus in the die-off has been inconclusive (Harwood et al. 1998), there are no indications that this agent, if it occurred before the event, was a significant cause of mortality for the seal population. Intoxication by PSP saxitoxins produced by dinoflagellates has been identified as another likely cause of mass mortality (Hernández et al. 1998), and it is likely that events of this type sporadically afflict the region, causing massive marine mammal mortalities (Maigret 1979). However, during the last 2 decades, when monitoring of the colony has been most comprehen- 
sive and population numbers are likely to have remained stable, no mass mortalities were detected until 1997.

Environmental changes affecting suitability of habitat appear to be major limiting factors. Cap Blanc is at the southern limit of the Saharan bank, a rich upwelling area considered to be one of the most important fishing areas in the world (Tilot 1993). This would, in principle, ensure food availability to seals. However, in recent years the whole region has been extensively overexploited by fishing, and this has been suggested as the reason for the currently low local population of cetaceans (Notarbartolo di Sciara et al. 1997). In particular, lobster, which was an important component of the diet of the Mediterranean monk seals in the 1980s, (Marchessaux 1989a) is no longer abundant and currently the composition of seal stomach contents is mostly restricted to fish and octopus (University of Las Palmas unpubl. data). Nevertheless, fish was considered the main prey item by Marchessaux (1989a), and there is no conclusive evidence that the lack of food is a limiting factor. Therefore, updated evidence of the state of these stocks is required for a sound analysis on the carrying capacity of the habitat. Because of the lack of clear evidence on whether the environment is actually limiting the growth of the colony, these and other additional aspects such as measures of reproductive success and the levels of pup mortality should be investigated further

Whatever the reason, the low numbers of seals surviving the 1997 mass mortality event and the persistence of possible limiting factors are likely to adversely affect the viability of the colony. From a demographic standpoint alone, small populations cannot persist long at a small size (Goodman 1987). Small populations are sensitive to changes in essential parameters; small differences in survival or reproductive success can cause changes in population growth rate from increases to declines (Eberhardt 1985). This is aggravated by the Allee effect, which is the sharp decrease in per capita survival and reproduction as population abundance decreases beyond a critical threshold level (Fretwell 1972); this effect is widely documented in extremely reduced populations of large mammals (Fowler \& Baker 1991). Moreover, range-fragmented populations with average positive growth may not persist because stochastic variation renders the risk of extinction high (Mangel \& Tier 1994).

The decrease of the Mediterranean monk seal colony at Cap Blanc by $66 \%$ in just 2 mo is a case in point. The risk of extinction of the colony after the mass mortality episode could be moderate provided that it is stable or expanding (Harwood et al. 1998), but the trajectory of the population before the event needs to be further assessed. A main threat is loss of genetic variability, which may be lost through genetic drift after the population decrease. Our analyses indicate that the number of adult seals, that is, those potentially contributing to reproduction, probably does not exceed about 77 individuals at present. This number may be even smaller because some degree of polygyny may exist in the species, as suggested by the sexual dimorphism in coloration and the territorial behavior of adult males (Marchessaux 1989a, University of Barcelona unpubl. data). While the minimum number of breeding individuals necessary to maintain genetic variability and overcome the effect of demographic stochasticity is unclear, a figure of around 50 has been suggested for many populations of large mammals (e.g. Franklin 1980, Gilpin \& Soulé 1986, Primack 1993). The genetic variability of Cap Blanc monk seals before the mass mortality event occurred was found to already be extremely low (Pastor et al. 1997), and it may decrease further in the near future as a result of population decrease. Preliminary modelling suggests that the decrease in allele diversity may be in the order of $12.5 \%$ (Harwood et al. 1998).

Moreover, our analysis shows that the change in the age composition of the colony was severe, resulting in a dramatic decrease in the number of adults. This change is likely to reduce the reproductive potential of the colony for at least 2 reasons. First, as a consequence of the rarefaction of adults in the coming years, the absolute number of reproductively active individuals will be even lower than overall population numbers would suggest. Second, the overall success of the reproductive segment is likely to decrease due to the increased contribution of young, recently matured individuals to reproductive tasks. In many pinniped species, it has been shown that older mothers have a higher weaning success than younger ones. This difference is attributed to an increase in size, previous mothering experience and social status with age (e.g. Payne 1979, Doidge et al. 1986, Sydeman et al. 1991, Lunn et al. 1994). However, some positive effects on reproduction are also expected from the decrease in population numbers produced by the die-off. In pinnipeds, pup mortality often has a density-dependent component (Doidge et al. 1986). The decrease in the density of hauled out individuals inside the caves is likely to permit use of optimal sectors of the relatively empty beaches by the motherpup pairs. Taking into account that the effect of storms appears to be the main cause of pup mortality in the colony (Gazo et al. 2000), this effect may be significant in permitting mothers to maximize the survival probability of their pups. Furthermore, the decrease in seal abundance is likely to lessen intraspecific competition for food. 
The resulting combination of these effects remains unclear, but the alteration in the age composition of the population is a further potential factor threatening colony stability in the near future. A study period of $6 \mathrm{yr}$, as the one carried out herein, is not long enough to properly understand the dynamics of the colony. Moreover, the high variance of the abundance estimate for the year in which the period initiates is a further difficulty and hampers the assessment of the population trajectory. While a rapid population change (e.g. a case of mass mortality) would be easily detected, this would be more difficult if a decline is slower over time. Other analyses of small marine mammal populations have shown similar limitations (e.g. Taylor \& Gerrodette 1993, Barlow et al. 1997, Wilson et al. 1999). Therefore, determining whether the colony at Cap Blanc is declining requires different assessment approaches, such as demographic analyses or the implementation of statistical methods with higher power to detect changes in abundance. Nevertheless, abundance estimates are still necessary for the implementation of management strategies, and as the basic input of demographic analyses.

Given the critical status of the colony after the mass mortality event in the spring of 1997 and the difficulties in the detection of population trends, further monitoring and reliable estimation of population parameters in the next few years are still required as an integral part of the effective management and conservation of the species. These parameters are required as an essential baseline for the development of further assessment of the viability of the colony, and a comprehensive evaluation of eventual mortalities. In this regard, our population analysis based on photo-identification can be valuable to produce such parameters, and of wider use for other small populations.

Acknowledgements. We are grateful to our colleagues from the University of Barcelona, Esteve Grau, Enric Badosa, Roser Samaranch, Gemma Cantos and Sonia Rey, for their participation in the field work and the analysis of the identification slides. The manuscript was improved with very valuable suggestions from Steve Buckland and 3 anonymous referees. Tim Gerrodette reviewed and improved the analysis of trends in abundance. Thanks are also due to Luis Mariano González (General Directorate for Conservation of Nature, Spain's Ministry of the Environment), Luis Felipe López Jurado (University of Las Palmas de Gran Canaria, Spain) and all the members of the University of Las Palmas and Isifer that contributed to make the fieldwork in Cap Blanc possible. The study was mainly funded by the European Commission LIFE Projects B4-3200/94/741 and B4-3200/96/510, and by the Emergency Plan for the Cap Blanc Monk Seal Colony funded by UNEP/GEF through a contract with the Netherlands Institute for Forestry and Nature Research (IBN/DLO). The European Nature Heritage Fund provided additional support in the early stages of the work

\section{LITERATURE CITED}

Aguilar A (1998) Current status of Mediterranean monk seal (Monachus monachus) populations. Regional Activity Centre for Specially Protected Areas (RAC/SPA), Tunis, Final report to Contract $14 / 97$

Barlow J, Gerrodette T, Silber G (1997) First estimates of vaquita abundance. Mar Mamm Sci 13:44-58

Bartholomew GA, Hubbs CL (1960) Population growth and seasonal movements of the northern elephant seal, Mirounga angustirostris. Mammalia 24:313-324

Bayed A (1994) Presentation succinte de la population de phoque moine du Sahara Marocain. In: Parc National de Dakhla. Plan d'amenagement. Secteur No. 2. Côte des Phoques. Document presented at the Meeting of Experts on the Evaluation of the Implementation of the Action Plan for the Management of the Mediterranean Monk Seal. Rabat, 7-9 October 1994 (Mimeo)

Borrell A, Aguilar A, Pastor T (1997) Organochlorine pollutant levels in Mediterranean monk seals from the western Mediterranean and Sahara coast. Mar Pollut Bull 34: 505-510

Boyd IL, Stanfield MP (1998) Circumstantial evidence for the presence of monk seals in the West Indies. Oryx 32 : $310-316$

Brasseur SMJM, Reijnders PJH, Verriopoulos G (1997) Mediterranean monk seal. In: Reijnders PHJ, Verriopoulos $G$, Brasseur SMJM (eds) Status of pinnipeds relevant to the European Union. IBN Sci Contrib 8:12-26

Burnham KP, Overton WS (1978) Estimation of the size of a closed population when capture probabilities vary among animals. Biometrika 65:625-633

Burnham KP, Overton WS (1979) Robust estimation of population size when capture probabilities vary among animals. Ecology 60:927-936

Burnham KP, Anderson DR, White GC, Brownie C, Pollock $\mathrm{KH}$ (1987) Design and analysis methods for fish survival experiments based on release-recapture. Am Fish Soc Monogr 5:1-437

Cantos G, Samaranch R, Badosa E, Grau E, Forcada J, Aguilar A (1998) Photo-identification catalogue of Mediterranean monk seals (Monachus monachus) from the western Sahara. In: Proceedings of the 11th Conference of the European Cetacean Society, Stralsund, Germany, 10-12 March 1997. Eur Res Cetaceans 11:300-301

Carothers AD (1973) Capture-recapture methods applied to a population with known parameters. J Anim Ecol 42: $125-146$

Carothers AD (1979) Quantifying unequal catchability and its effect on survival estimates in an actual population. J Anim Ecol 48:863-869

Chao A (1989) Estimating population size for sparse data in capture-recapture experiments. Biometrics 45:427-438

Chao A, Lee SM, Jeng SL (1992) Estimating population size for capture-recapture data when capture probabilities vary by time and individual animal. Biometrics 48: $201-216$

Darroch JN (1958) The multiple recapture census. I. Estimation of a closed population. Biometrika 45:343-359

Doidge DW, McCann TS, Croxall JP (1986) Attendance behavior of Antarctic fur seals. In: Gentry RL, Kooyman GL (eds) Fur seals: maternal strategies on land and at sea. Princeton University Press, Princeton, NJ, p 102-1.14

Durant SM, Harwood J (1992) Assessment monitoring and management strategies for local populations of the Mediterranean monk seal (Monachus monachus). Biol Conserv $61: 81-92$ 
Eberhardt LL (1969) Population estimates from recapture frequencies. J Wild] Manag 33:28-39

Eberhardt LL (1985) Assessing the dynamics of wild populations. J Wildl Manag 49:997-1012

El Amrani M. Hajib S, Robert P, Escoubet P (1992) Observations sur la population de phoque moine (Monachus monachus) entre le Cap Barbas et la pénınsule du Cap Blanc. Conservation of the Mediterranean monk sealtechnical and scientific aspects. Environ Encounters 13: $25-29$

Forcada J, Aguilar A (1996) Assessment of the reliability of photographic identification of Mediterranean monk seals (Monachus monachus). LIFE Project B4-3200/94/741, Viabilidad de la colonia de la foca monje (Monachus monachus) de la península de Cabo Blanco. Final Report. December 1996

Fowler CW, Baker JD (1991) A review of anima population dynamics at extremely reduced population levels. Rep Int Whal Comm 41:545-554

Francour P, Marchessaux D, Argiolas A, Campredon P, Vuignier L (1990) La population de phoque moine (Monachus monachus) de Mauritanie. Rev Ecol Terre Vie 45:55-64

Franklin IR (1980) Evolutionary change in small populations. In: Soulé ME, Wilcox BA (eds) Conservation biology: an evolutionary-ecological perspective. Sinauer Associates Inc, Sunderland, MA, p 135-149

Fretwell SD (1972) Populations in a seasonal environment. Princeton University Press, Princeton, NJ

Gazo M. Aparicio F, Cedenilla F, Layna JF, González LM (2000) Breeding success and pup survival in the Mediterranean monk seal (Monachus monachus) colony of the Cabo Blanco peninsula (western Sahara-Mauritania). Mar Mamm Sci 16 (in press)

Gerrodette T (1993) TRENDS: software for a power analysis of linear regression. Wildl Soc Bull 21:515-516

Gilmartin WG, Eberhardt LL (1995) Status of the Hawaiian monk seal (Monachus schauinslandi) population. Can J Zool 73:1185-1190

Gilpin ME, Soulé ME (1986) Minimum viable populations: processes of species extinction. In: Gilpin ME, Soulé ME (eds) Conservation biology. The science of scarcity and diversity. Sinauer Associates, Inc, Sunderland, MA, p $19-34$

González LM, Aguilar A, López-Jurado LF, Grau E (1997) Status and distribution of the Mediterranean monk seal Monachus monachus on the 'Cabo Blanco' Peninsula (western Sahara-Mauritania) in 1993-1994. Biol Conserv $80: 225-233$

Goodman D (1987) The demography of chance extintion. In Soulé ME (ed) Viable populations for conservation. Cambridge University Press, Cambridge

Grau E, Aguilar A, González J, San-Félix M, González LM López-Jurado LF (1994) Photoidentification of Mediterranean monk seals (Monachus monachus) off the coast of the southern Sahara. In: Proceedings of the 8th Annual Conference of the European Cetacean Society, Montpellier, France, 2-5 March 1994. Eur Res Cetaceans 8 $279-280$

Gruvel MA (1924) Quelques observations zoologiques faites au cours d'un voyage en Mauritanie. Bull Soc Natl Aclim France $71: 13-14$

Hammond PS (1986) Estimating the size of naturally marked whale populations using capture-recapture techniques. Rep Int Whal Comm (Spec Issue) 8:253-282

Harwood J, Lavigne D, Reijnders P (1998) Workshop on the causes and consequences of the 1997 mass mortality of Mediterranean monk seals in the western Sahara. Amster- dam, 11-14 December 1997. IBN Sci Contr 11:1-32

Hernández M, Robinson I, Aguilar A, González LM, LópezJurado LF, Reyero MI, Cacho E. Franco J, López-Rodas V. Costas E (1998) Did algal toxins cause monk seal mortality? Nature (Lond) 393:28-29

Hiby AR, Jeffery JS (1987) Census techniques for small populations, with special reference to the Mediterranean monk seal. Zool Symp 58:193-210

IUCN (International Union for Conservation of Nature) (1996) Red list of threatened animals. IUCN, Gland

Lee SM, Chao A (1994) Estimating population via sample coverage for closed capture-recapture models. Biometrics 50: $88-97$

Lunn NJ, Boyd IL, Croxall JP (1994) Reproductive performance of female Antarctic fur seals: the influence of age, breeding experience, environmental variation and individual quality. J Appl Ecol 63:827-840

Maigret J (1979) Les échouages massifs des cétacés dans la région du Cap-Vert (Sénégal). Notes Africaines (Université de Dakar) 161:23-28

Mangel M. Tier CH (1994) Four facts every conservation biologist should know about persistence. Ecology 75:607-614

Marchessaux D (1989a) Recherche sur la biologie, l'ecologie et le statut de phoque moine, Monachus monachus. GIS Posidonie Publ, Marseille

Marchessaux D (1989b) Distribution et statut des populations de phoque moine Monachus monachus (Hermann, 1779) Mammalia 53:621-642

Miller RG (1981) Simultaneous statistical inference, 2nd edn. Springer-Verlag, New York

Monod I (1923) Note sur la présence de Monachus albiventer Bodd. sur la côte saharienne. Bull Mus Natl Hist Nat 29: $555-557$

Morales-Agacino E (1945) Algunos datos sobre ciertos mamíferos del Sáhara occidental. Bol R Soc Esp Hist Nat Secc Biol 43:199-212

Morales-Agacino E (1950) Notes sur le phoque moine (Monachus monachus Herman.) du littoral saharien espagnol Mammalia 14:1-6

Notarbartolo di Sciara G, Politi E, Bayed A, Beaubrun PC Knowlton A (1997) A winter cetacean survey off southern Morocco, with a special emphasis on suitable habitats for wintering right whales. Doc SC/49/03, International Whaling Commission, Cambridge

Osterhaus A, Groen J, Niesters H, van de Bildt M, Martina B Vedder L, Vos J, van Egmond H, Sidi BA, Barham MEO (1997) Morbillivirus in monk seal mass mortality? Nature (Lond) 388:838-839

Otis DL, Burnham KP, White GC, Anderson DR (1978) Statis tical inference from capture data on closed animal populations. Wildl Monogr 62:1-135

Pastor T, Allen P, Amos W, Aguilar A (1997) DNA microsatellites in Mediterranean monk seals. Eur Res Cetaceans 10:321-324

Payne MR (1979) Growth in the Antarctic fur seal Arctocephalus gazella. J Zool (Lond) 187:1-20

Pollock KH, Nichols JD, Brownie C, Hines JE (1990) Statistical inference for capture-recapture experiments. Wild Monogr 107:1-97

Primack RB (1993) Essentials of conservation biology. Sinauer Associates, Inc, Sunderland, MA

Rexstad EA, Burnham KP (1992) User's guide for interactive program CAPTURE. Colorado Cooperative Fish and Wildlife Research Unit, Colorado State University, Ft. Collins

Seber GAF (1982) The estimation of animal abundance and related parameters. Griffin and Co L.td, London 
Stewart BS, Yochem PK, Huber HR, De Long RL, Jameson RJ, Sydeman WJ, Alle SG, Le Boeuf BJ (1994) History and present status of the Northern elephant seal population. In: Le Boeuf BJ, Laws RM (eds) Elephant seals: population ecology, behavior, and physiology. University of California Press, Los Angeles, p 1-27

Sydeman WJ, Huber HR, Emslie SD, Ribic CA, Nur N (1991) Age-specific weaning success of northern elephant seals in relation to previous breeding experience. Ecology 72 : $2204-2217$

Taylor BL, Gerrodette T (1993) The uses of statistical power in conservation biology: the vaquita and northern spotted owl. Conserv Biol 7:489-500

Thompson SK (1992) Sampling. Wiley-Interscience, New York

Tilot V (1993) Description of the different large marine eco-

Editorial responsibility: Otto Kinne (Editor).

Oldendorf/Luhe, Germany systems of West Africa. IUCN Marine Program Project No. 9897. Large Marine Ecosystem, IUCN

University of Barcelona (1997) Actuaciones para la recuperación de la foca monje (Monachus monachus) en el Atlantico. Report of Contract B4-3200/96/510 (LIFE program), European Commission, Brussels

Valverde JA (1957) Aves del Sáhara español. Instituto de Estudios Africanos, Madrid

White GC, Anderson DR, Burnham KP, Otis DL (1982) Capture-recapture and removal methods for sampling closed populations. LA-8787-NERP, Los Alamos National Laboratory, Los Alamos, NM

Wilson B, Hammond PS, Thompson PM (1999) Estimating size and assessing trends in a coastal bottlenose dolphin population. Ecol Appl 9:288-300

Submitted: January 14, 1999; Accepted: June 2, 1999

Proofs received from author(s): October 20, 1999 